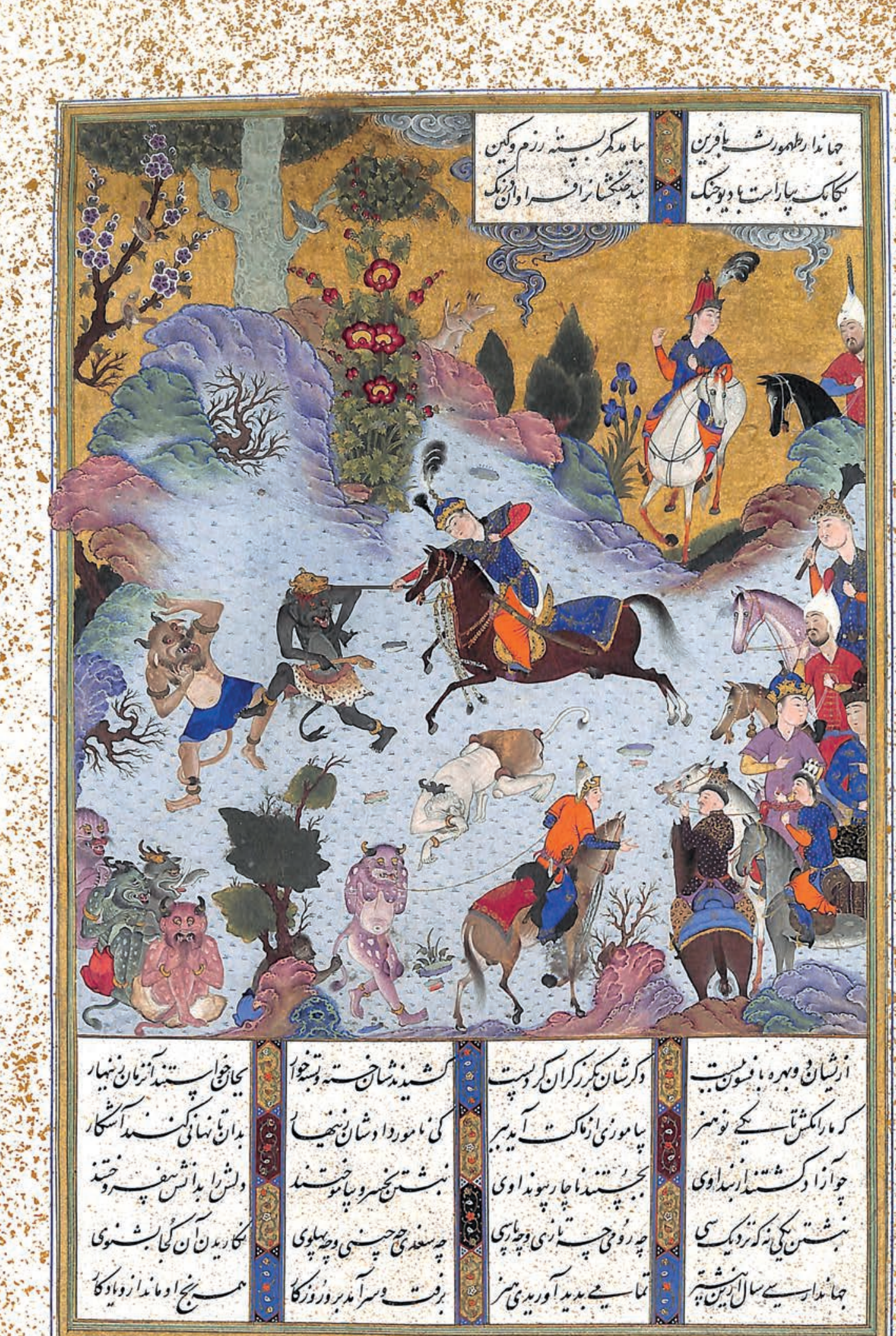




\title{
De maldiciones y bendiciones: el poder de la palabra como catalizador en la mitología de la India
}

\author{
From Curse to Boons: The Power of the Word as a Catalyst \\ in some Literary Works of Hindu Mythology
}

\author{
YogendRa SHARMa \\ Escuela Nacional de Lenguas, Lingüística y Traducción, uNAM \\ Gurudev Tagore Indian Culture Center (Embajada de la India en México)
}

RESUMEN: Muchas veces, lo que parece maldición en los paisajes mitológicos de la India no es más que un recurso que desata todo un viaje literario sobre las fuerzas divinas interviniendo en las vidas humanas con el objetivo de impartir las enseñanzas y dejarnos una riqueza narrativa.

ABSTRACT: Oftenly, what appears to be a curse in Indian mythological texts is nothing but an excuse that unbinds an entire literary odyssey of the divine forces intervening in human lives to leave the ethical and moral teachings and a rich literature. Curiously, not even gods are excluded from carrying the burden of a curse and to pay for their unethical acts and they have to be incarnated as earthly beings to accomplish their role which seems to be a divine comedy when seen from a celestial perspective, however, contains the elements of a human tragedy when seen from a terrane view.

PALABRAS ClAVE: poder, palabra, maldición, mitología, hinduismo.

KEYwORDS: power, word, curse, mythology, Hinduism.

RECIBIDO: 8 de junio de 2017 • AcEPTADO: 2 de agosto de 2017 



\section{YogendRa SHARMA}

Escuela Nacional de Lenguas, Lingüística y Traducción, UNAM

Gurudev Tagore Indian Culture Center

(Embajada de la India en México)

\section{De maldiciones y bendiciones: el poder de la palabra como catalizador en la mitología de la India}

La palabra, tanto escrita como articulada, es un concepto relevante en el ámbito filosófico, lingüístico, místico y religioso, sobre todo de la India antigua. Por ejemplo, uno de los mil nombres de Kŗ̧̧̧a ${ }^{1}$ o Śiva² es

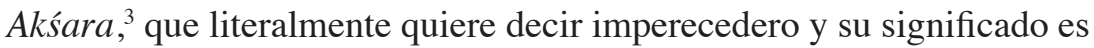
palabra o letra. En muchos pasajes de los libros sagrados o religiosos, es posible percibir que el poder de la palabra se adquiere mediante la atención y el respeto que se ofrecen al sonido y al significado de ésta. De hecho, es gracias a la práctica constante de ambas acciones que los seres alcanzan el poder de que todo aquello que enuncien se realice. En palabras sencillas, se puede decir que hablar siempre con la verdad convierte lo que se dice en la verdad misma.

1 La transliteración de las palabras de sánscrito es según International Alphabet of Sanskrit Transliteration.

Kŗşya es el octavo avatāra de Viş̧u. Es una de las deidades más adoradas por los hindúes y también es el personaje principal de varias escrituras importantes del hinduismo.

2 Junto con Vişnu es una de las deidades más adoradas por los hinduistas. Tiene mil nombres que simbolizan sus atributos. En el "trimurti" hinduista, se le presenta como el dios de la destrucción o la disolución.

3 Significa imperecedero o indestructible. Su significado en lenguaje cotidiano es "letra". 
Este artículo tiene por objetivo dar un breve panorama acerca del poder de la palabra en algunas obras literarias y purāyicas ${ }^{4}$ del hinduismo. Para ello, se delinearán algunos pasajes en los cuales se puede percibir el uso de este poder en sus diferentes versiones e intensidades. Antes de continuar, es necesario explicar las dos nociones que se discuten en el ensayo: śa $\bar{a} a^{5}$ y $v a r a,{ }^{6}$ las cuales, en este contexto, se traducen como maldición y bendición respectivamente. Ambas son manifestaciones del poder de palabra que los seres humanos y celestiales alcanzan a través de seguir voluntariamente ya sea una vida ética, o sea tapas ${ }^{7}$ (mortificación o penitencia), o también por haber complacido a alguna de las fuerzas supremas del panteón del hinduismo. Por ejemplo, en Bhāgavata Purāya, Śiva le dice a $r s ̧ i^{8}$ Mārkandeya: $9^{~}$ Brahmā, ${ }^{10}$ Viş̧u ${ }^{11}$ y yo, los tres somos capaces de dar bendiciones (o poderes) y nuestra aparición nunca resulta ser sin fruto" (Vyāsa ${ }^{12}$ 2004: 59).

Estas tres fuerzas cósmicas - Brahmā (el Creador), Vişnu (el que sostiene la Creación) y Śiva (el que destruye o transforma la existencia manifiesta) - cumplen deseos a los seres humanos y divinos concediéndoles los poderes anhelados. Al momento de concederlos, las tres deidades toman en cuenta las leyes de la naturaleza que ellos mismos crea-

$4 \quad$ Los purāyas son textos sagrados que primero existieron en la tradición oral y que contienen narraciones acerca de la cosmología, el comienzo y el fin del universo, y la historia de las dinastías de los reyes.

5 Maldición.

6 Bendición, don o poder místico o sobrehumano que uno adquiere por sus esfuerzos.

7 Literalmente significa "calor", sin embargo, puede interpretarse como penitencia, ferviente y constante esfuerzo.

8 Poeta místico, sabio, el que tiene el conocimiento espiritual.

$9 \quad$ Rş̧i mencionado en varios purāyas y en el Mahābhārata. Uno de los purāyas lleva su nombre.

10 Se puede traducir como "la expansión". En el "trimurti" hinduista, se le presenta como el Creador del universo y tiene varios nombres.

11 Se puede traducir como "el que está impregnado en todo". En el "trimurti" hinduista, se le presenta como el dios que sostiene la Creación. Sus diez avatares es un tema recurrente en los textos antiguos.

12 Tradicional y mitológicamente, Vyāsa es considerado el autor de muchas de las obras de la literatura sagrada del hinduismo. Su nombre es Krş̧a Dvaipāyana y también es conocido como Veda Vyāsa por haber compilado los Vedas, además de ser el cronista de Mahābhārata y varios Purāyas. 
ron. Un ejemplo de esto es el de Narasimha ${ }^{13}$ (hombre-león), avatāra de Viş̧u. Se cuenta que Hirayyakaśyapa ${ }^{14}$ hace fervientes e imposibles penitencias para complacer a Brahmā. Cuando aparece el Caturmukha ${ }^{15}$ y le pregunta qué desea, Hiranyakaśyapa le pide la inmortalidad. El Nacido-de-loto ${ }^{16}$ le dice que esto es imposible puesto que todo lo que nace está destinado a morir. El devoto le pide entonces que cumpla su siguiente deseo: que él no muera ni de día ni de noche, ni en su casa ni fuera de ésta, ni en la tierra ni en el cielo, ni a causa de un arma de lanzar ni por una de duelo y que no lo pueda matar ni hombre ni animal. El Dios-de-la-palabra cumple el deseo del rey Hiranyakaśyapa, quien no tarda en abusar de su poder y ejercer su tiranía aun sobre los seres humanos y las deidades. Para poner fin a Hiranyakaśyapa, "Vishnu, in the form of a being half-man and half-lion, came forth from the pillar, laid hold of Hiranyakasipu by the thighs with his teeth, and tore him up the middle" 17 (Wilkins 1900: 64) respetando, palabra por palabra, la "bendición" de Brahmā al rey. Se ve claramente la astucia de Viş̧u, quien hace una lectura entrelíneas de la bendición que el rey recibe y que se convierte en la causa de su muerte.

Se ha mencionado que, al momento de conceder deseos, las deidades consideran las leyes de la naturaleza que crearon; no obstante, sólo en ciertas circunstancias Śiva y Viş̧u deciden quebrantar estos límites. Así, en una ocasión, a pesar de que una pareja de sabios no estaba destinada a tener ningún hijo en esta vida, debido a su ferviente tapas, Śiva - en algunas versiones Brahmā- les da la opción de tener un hijo tonto y longevo o uno sabio que muriera a los 16 años. La pareja opta por un hijo sabio de nombre Mārkandeya, quien resulta ser un gran devoto de Śiva. Cuando está por cumplir los 16 años, este niño sabio se sumerge en una profunda meditación acerca de Śiva. Durante ese tiempo, el dios de la muerte $-\mathrm{K}_{\bar{a}} \mathrm{a}^{18}$ o Yama - se le acerca, pero inclusive la

\footnotetext{
13 El cuarto avatāra de Visnu en la forma de hombre-león.

14 Un poderoso asura, archienemigo de los devas.

15 Uno de los nombres de Brahma que significa "el de cuatro caras".

16 Uno de los nombres de Brahma, ya que nace en una flor de loto.

17 Vişnu, en la forma de un ser mitad hombre y mitad león, surgido de un pilar, agarra con sus dientes a Hiranyakaśyapa por los muslos y lo parte en dos.

18 Tiempo o muerte.
} 
muerte encuentra su fin a manos de Śiva, porque el Kalāntaka ${ }^{19}$ decide salvar a su devoto y cambiar lo que estaba destinado para Mārkandeya.

Curiosamente, se advierte con frecuencia que son los místicos y sabios $r$ şis los que usan su poder de palabra para "castigar" a los seres humanos y a las deidades maldiciéndolos. Un nombre que sobresale en esta función es ŗş̧i Durvāsā - cuyo nombre significa "con quien es difícil vivir" y cuyo nacimiento se debe a la ira de Śiva-. Rş̧i Durvāsā no únicamente es muy poderoso, sino también es capaz de dar poderes a otros seres, pero es especialmente conocido, o, mejor dicho, temido, por su comportamiento volátil. En varios pasajes importantes en la literatura sánscrita, sus maldiciones funcionan como catalizadores para comenzar o dar un giro a la historia. Cabe mencionar tres de las ocasiones más sobresalientes. No obstante, antes de presentar estos ejemplos, es pertinente mencionar que es común encontrar diferentes versiones del mismo pasaje mitológico en la literatura de la India antigua. Escasas veces es significativa la diferencia y generalmente ésta no cambia la trama principal. Pasemos entonces a los pasajes.

El primero es el famoso samudra-manthan ${ }^{20} \mathrm{o}$ batimiento del océano que se encuentra en Bhagavata Purāna, Viş̧u Purāna, Mahābhārata y otras escrituras. En este pasaje, cuando Brahmā percibe que "por el śāpa de Durvāsā los tres mundos e incluso Indra (el rey de los dioses) han perdido su gloria" (Vyāsa 2004: 437), les aconseja a los debilitados suras o devas (las deidades) que pidan a los asuras, sus enemigos por excelencia, juntar fuerzas para llevar a cabo la labor de batir el océano, con el objetivo de sacar el néctar de la inmortalidad - amrtam - ${ }^{21}$ para compartirlo equitativamente. Se prepara esta ardua hazaña colocando a la serpiente Vāsuki ${ }^{22}$ alrededor de la montaña Mandara, que a su vez está ubicada en medio del océano. Como consecuencia del samudra-manthan emergen muchas cosas, tales como joyas y armas

19 El que mata a la muerte. Śiva gana este nombre por matar a Kāla para salvar a su devoto Mārkandeya. Él es la personificación de la ira de Śiva.

20 Literalmente quiere decir "el batimiento del mar u océano". Es uno de los pasajes más contados en los textos sagrados.

21 Néctar o bebida de la inmortalidad.

22 La serpiente que está en el cuello de Śiva. La usan como una soga o cuerda para batir el océano. 
divinas, los seres y animales celestiales, el veneno, etcétera, antes de que salga el amrtam. Los asuras arrebatan a los suras la bebida y Vişıu toma la forma de Mohini ${ }^{23}$ - la mujer encantadora - para robársela con la finalidad de repartirla entre los dioses.

Varias preguntas surgen: ¿por qué los dioses tuvieron que recurrir a esto? o ¿por qué estaban debilitados ante los asuras? Por la maldición del ŗşi Durvāsā. Una vez Indra, el rey de los dioses, montado en su elefante Airāvata, ${ }^{24}$ se encuentra con $r$ ş̧i Durvāsā quien le obsequia un collar de flores divino, regalo de Śiva. Indra lo coloca sobre el tronco del elefante quien lo tira al suelo. Durvāsā lo toma como un acto prepotente de parte del rey de los dioses y lo maldice para que los dioses pierdan su fuerza y fortuna, pues el collar era un objeto divino y no se merecía este desprecio. Indra intenta explicar al rsşi lo sucedido, pero su tentativa resulta en vano.

El segundo pasaje es de la obra Abhijñānasākuntalam ${ }^{25}$ de Kalidāsa, que está inspirada en un paisaje del Mahābhārata. En esta obra maestra del renombrado poeta, el rey Duşyanta contrae el matrimonio gandharva ${ }^{26}$ con Śakuntala, en ausencia del padre adoptivo de la protagonista, y se va prometiéndole que pronto volverá a verla. A la mitad de la obra, aparece $r s ̧ i$ Durvāsā:

Era este, un asceta mendigo, el temible Durvasa, quien, por sus austeridades, poseía fuerza dominadora nunca sobrepujada. Indignose al ver que no acudía la doncella a recibirlo como debiera, y tomó su ausencia por desprecio de su anciana austeridad. Levantando el puño cerrado hacia los cielos, exclamó: - ¡O Shakuntala!, ¡mujer cuyos sueños van hacia el hombre que ama, y desprecia al huésped venerable que pasa por su puerta! tu Rey va a olvidarte. No recordará que te vio; no recordará que te amó, y será se-

23 Significa la mujer encantadora o hechicera. Visnu toma esta forma para robar amrtam a los asuras y distribuirlo entre los devas.

24 El elefante que salió cuando fue batido el océano. Indra lo toma para usarlo como su vehículo.

25 Es considerada como la mejor obra escrita en sánscrito por Kālidāsa, uno de los escritores más importantes en la literatura sánscrita y se inspira en un episodio del Mahābhārata.

26 Una de las ocho maneras de uniones (o matrimonios). Sin necesidad de que la familia esté presente, "cuando el hombre y la mujer contraen matrimonio por el gusto mutuo, lo llaman gandharva" (Vātsyayanamuni 1999: 280). 
mejante a un hombre que obró bajo el influjo de la embriaguez, y quien al despertarse no puede repetir las palabras que pronunció en tal estado. (Eulate 2002: 42).

Las dos amigas de Śakuntala abogan por ella ante el ŗşi, quien debilita su maldición puntualizando que cuando el rey vea un objeto que él había regalado a la joven se va a acordar de ella completamente.

El tercer pasaje es de una bendición (o poder) que rş̧i Durvāsā otorga a la reina Kunti, madre de los cinco hermanos protagonistas del Mahābhārata. La princesa Pṛthā - otro nombre de Kunti - en su adolescencia cumplió todos los deberes de una buena anfitriona sirviendo al rsşi Durvāsā quien, al estar complacido, le comparte un mantra con cuyo poder ella podía invocar a cualquier deidad para que le diera un hijo. Cuando el $r$ şi se va del palacio, la princesa, por curiosidad, invoca al Sol, quien le deja un hijo. Por miedo a la difamación, la adolescente decide abandonar al niño en el río.

Dos aspectos llaman la atención en estos tres ejemplos del uso del poder de la palabra, llámese śāpa o vara (bendición o maldición). Por una parte, la intensidad de la maldición varía. En el caso de Indra, Durvāsā castiga a todos los dioses por algo que podría parecer un descuido mínimo y sin intención y, a pesar de pedirle perdón, el rsşi decide no disminuir el castigo. Por otro lado, en el caso de Śakuntala, el castigo es reducido. El tercer caso es todavía más interesante, lo que parece una bendición para Kunti, se convierte en una maldición, puesto que la curiosidad por averiguar el poder de la bendición lleva a la princesa a vivir con el remordimiento de haber abandonado a su hijo. Así, una maldición puede reducirse y lo que parece ser una bendición puede hacer sufrir al beneficiario.

Este último ejemplo permite introducir el texto del que se retoman los pasajes que a continuación se presentan, me refiero al Mahābhārata, una de las dos epopeyas más importantes de la literatura sánscrita — otra es el Rāmāyana - y una de las obras literarias más extensas escritas hasta ahora. En el primer libro de este compendio se admite que todo está en este libro: "धर्मे चार्थे कामे च मोक्षे च भरत भभ। यदिहास्ति तदन्यत्र यन्नेहास्ति न तत् क्वचित्।।" dharma, artha, kāma y moksha (los cuatro purusārthas) ${ }^{27}$ se encuentran

Según el hinduismo, todas las acciones del ser humano tienden a tener como obje- 
en el Mahābhārata - lo que no está aquí no está en ningún otro lado(Vyāsa 2004: 56.33).

Esta cita marca la importancia de este libro en el hinduismo y la razón por la que escogí algunos de sus pasajes para analizar dentro del contexto de este artículo.

Pasemos entonces a describir la importancia del papel y el poder de la palabra en este libro que se enorgullece de contener absolutamente todo acerca de lo humano y lo divino, y lo describe en más de un millón de palabras.

Tradicionalmente ŗşi Vyāsa es considerado como el autor del Mahäbhärata. No hay que olvidar, sin embargo, que, como sucede con la mayoría de los textos antiguos, la cuestión de una autoría única es debatible. Probablemente, a lo largo del tiempo, algunos pasajes se añadieron y otros se fueron quitando del texto original. En ese sentido, explicar los procesos de redacción que experimentó la epopeya hasta llegar a su forma actual es un tema que merece una investigación aparte, por ello sólo mencionaré tres de los "textos" más reconocidos: Jaya (8 800 versos dictados por Vyāsa), Bhārata (24 000 versos recitados por Vaiśampāyana) y Mahābhārata con poco más de 100000 versos narrados por Ugraśrava Sauti. Este libro no tiene una narración lineal o unidireccional; hay textos entre textos. De hecho, algunos pasajes del libro han cobrado tanta importancia que parecen tener "vida propia". Un ejemplo evidente es de la Bhagavadgitā. No obstante, la historia principal trata sobre la dinastía Bharata, específicamente acerca de los antecedentes, la batalla y las represalias que ésta tuvo entre los hijos de los hermanos Pāndu y Dhŗtrāşţra.

En las páginas que siguen brindo la lectura de algunos pasajes de esta epopeya tomando en cuenta el tema del poder e importancia de la palabra (o promesa). No sería prudente ni posible analizar todo el libro;

tivo dharma, artha o kāma. Y cumplir estos tres objetivos nos lleva hacia el mokśa . Dharma se podría traducir como el deber, la ética, el bien, el orden, etcétera. Artha se podría interpretar como la abundancia que provee comodidad para todos, y este bienestar material incluye dinero, oro, ganadería, casas, ropas, familia, amigos, etcétera. Kāma es el placer sensorial. Estos tres objetivos, cumplir el deber, ser abundante y sentir placer - dharma, artha y käma nos conducen a nuestra verdadera naturaleza- mokśa: la liberación, que es el destino final y el objetivo esencial de una vida humana. 
por ende, me limitaré a algunos pasajes que considero importantes para el argumento principal de este artículo.

Comencemos nuestro recorrido a través de la epopeya con Bhīşma, el hijo de Sāntanu y Gangā - la personificación del río Ganges - quien se encuentra entre los personajes principales del Mahābhārata. Tío-abuelo de los kauravas y los pāndavas, Bhīşma posee casi todas las cualidades y virtudes de un ser ideal: guerrero invencible, adiestrado en todo tipo de armas, hijo obediente, poseedor del conocimiento de los vedas y otras escrituras sagradas. Es posible argumentar que, sin este personaje, no existiría el libro ni la batalla del Mahābhārata. En ese sentido, es irónico que su nacimiento se deba a una maldición.

Uno nace porque desea o porque no puede superar sus deseos. El nacimiento de los seres se debe a los deseos para su propio beneficio o placer. Cuando una deidad o un ser celestial comete algo indebido es castigado y debe nacer como ser humano. Esto es lo que sucede con Bhīşma. Él es uno de los ocho hermanos celestiales vasus. ${ }^{28}$ En el libro 1 de esta epopeya, la historia cuenta que en una ocasión estos ocho hermanos, acompañados de sus esposas, visitaron el āśram ${ }^{29}$ de ,̧şi Vaśiş̧̧һ.$^{30}$ La esposa de Prabhāsa (Dyaus) se queda fascinada con Kāmadhenu ${ }^{31}$ - la vaca divina regalo de los dioses al rsşi- por lo que pide a su esposo que la robe. Prabhāsa comete el error de hurtarla con ayuda de sus hermanos. Como castigo a este acto, $r$ şi Vaśiş̧h ma maldice a los ocho hermanos anunciándoles que nacerán como seres humanos. Los vasus ruegan al rssi que los perdone. Éste reduce su maldición para siete de ellos, quienes vivirán una vida muy corta como seres humanos; sin embargo, no levanta el castigo a Prabhāsa, pues como protagonista del robo tendrá que vivir una vida humana muy larga.

Ganga, el río celestial, promete a los ocho vasus que los liberará de sus cuerpos humanos en cuanto nazcan. La unión de Gangā con

28 Ocho deidades que asisten a Indra en la forma de los elementos de la naturaleza, por ejemplo, prthvī (tierra), agni (fuego), vāyu (aire), etcétera.

29 Lugar donde se estudia y se practica una vida espiritual.

30 Es un rsi védico reverenciado y mencionado en varios purāyas y epopeyas de la India.

31 Vaca divina que sale del batimiento del océano. Su nombre significa "la que cumple todos los deseos". 
Sāntanu -el futuro padre de los ocho vasus - también tiene una maldición como antecedente. Śāntanu, en su vida anterior, era un virtuoso rey quien fue invitado a la corte divina para participar en una reunión. Mientras todos los dioses estaban rezando a Brahmā, el viento sopló descubriendo el cuerpo de Gangā. Con excepción del rey, todas las deidades bajaron su mirada como una muestra de respeto hacia Gangā. Por este acto indebido, Brahmā lo maldice presagiándole que su deseo carnal por Gangā sería la causa de sufrimiento en su siguiente vida.

La ejecución de la maldición comienza con una descripción romántica cuando el rey Śāntanu mira por primera vez a la mujer Gangā caminando en la orilla del río Ganges. Se enamora a primera vista y le pide ser su esposa. Gangā otorga su consentimiento con la condición de que no cuestione ninguno de sus actos, pues, en cuanto lo hiciera, ella lo abandonaría. El enamorado rey no encuentra inconveniente alguno en aceptar esta condición. Una vez casada, para cumplir sus palabras, Gangā libera uno por uno a los siete vasus nacidos en forma de sus hijos ahogándolos en el río, mientras el rey sufre viéndola "matar" a los bebés. Sāntanu, no pudiendo tolerar más la situación, cuando ve a Gangā llevar a su octavo hijo recién nacido al río, cuestiona su cruel acto. En ese momento, Gangā le cuenta la historia de los hermanos vasus y abandona al rey prometiéndole que regresará a su octavo hijo, luego de haberlo preparado para la dura vida que había de enfrentar. Transcurren aproximadamente doce años para que Bhīşma sea devuelto a su padre. Durante este tiempo, el príncipe recibe el conocimiento de los mejores maestros, sabios en el arte de la guerra y de las escrituras sagradas. Con el paso del tiempo, el príncipe logra ganar el amor y respeto no sólo de su padre sino de todo el pueblo; por tanto, es nombrado el siguiente heredero al trono.

Sanntanu vive todo este tiempo en celibato, mas, en una ocasión, cuando va de cacería, se encuentra con Satyawati y se enamora de ella. El padre de Satyawati permite que el rey contraiga matrimonio con su hija a condición de que sean sus hijos los herederos del reino. El rey rechaza esta propuesta. Al enterarse del deseo de su padre, Bhīşma no únicamente abandona el trono sino que toma el voto de vivir una vida célibe para evitar que sus hijos quieran reclamar el derecho sobre el trono. A cambio de este voto tan enérgico, Śāntanu otorga a su hijo el poder sobre su propia muerte. Es decir, Bhīşma podía escoger la hora 
de su fallecimiento. Él promete a Śāntanu cuidar siempre el trono, ver la imagen de su padre en el que fuera rey y no dejar que la muerte se le acerque hasta ver el reino protegido bajo el mandato de un buen rey.

Para resumir, tenemos a un ser celestial en la forma de un ser humano capaz de vencer a los dioses por sus armas, atado por su voto al servicio del trono sin importar quien fuera el rey, con el poder sobre su propia muerte, pero obligado a vivir hasta que el reino esté protegido. El castigo de $r$ ş̧i Vaśişţha, en vez de una maldición, parece ser un catalizador para el comienzo de una de las historias más intrigantes y perfectas que existen en la literatura escrita y oral.

Śāntanu muere dejando con Satyawati dos hijos. Irónicamente, ninguno de los dos reinó por mucho tiempo. Ambos mueren jóvenes, uno antes de casarse y el segundo, pese a casarse con dos princesas, fallece sin dejar ningún heredero. Satyawati convoca a Vyasa, el hijo que tuvo cuando era soltera, para que, bajo la costumbre de Niyoga, ${ }^{32}$ le dé un heredero. Mediante la unión de Vyāsa con Ambikā y Ambālika nacen Dhṛtrāş̧̧ra y Pāndu respectivamente. No obstante, al alcanzar la edad de gobernar, Dhr̆trāşţra no puede heredar el trono por ser ciego de nacimiento y su hermano menor, Pāndu, es coronado rey. El hermano ciego se casa con Gāndhāri y Pāndu con Kunti y Mādri. Acompañado de sus dos esposas, Pāndu va a un bosque con el fin de descansar de sus deberes reales, dejando el trono a cargo de su hermano mayor, a quien protege su tío-abuelo Bhīşma.

Un día en el bosque, durante una cacería, Pāndu mata sin saber a una pareja de $r$ şis quienes estaban en el acto de hacer el amor. Antes de morir, el rş̧i castiga al rey maldiciéndolo con la muerte si éste se acerca a alguna mujer con deseo de hacer el amor. Después de este triste acontecimiento, Pāndu deja el reino a manos de Dhŗtrāş̧̧ra y se retira al bosque, acompañado de sus esposas, para vivir como un asceta. En una ocasión Pāndu muestra tanta tristeza por no haber dejado ningún

32 Es una tradición antigua mencionada en algunos libros. Por ejemplo, en Manusmrti (capítulo 9, versos 57-69) se dice que si una mujer no tiene hijos porque su esposo es incapaz de dárselos o ya ha fallecido, ella puede solicitar a un hombre (por lo general familiar) para ayudarla a procrear. Esta costumbre tenía normas muy claras: no era un acto para adquirir placer; el padre biológico no tendría ningún beneficio ni derecho sobre el niño; para evitar el uso equivocado de la tradición, sólo se podían pedir tres encuentros, etcétera. 
heredero que Kunti le cuenta sobre el mantra que rsşi Durvasa le había concedido, pero omite el detalle de haber tenido un hijo con el Sol. Con el consentimiento de Pāndu, Kunti tiene tres hijos: Yudhisţhira con Dharma; ${ }^{33}$ Bhīma con Vayu ${ }^{34}$ y Arjuna con Indra. La reina comparte el mantra con Mādri, quien invoca a los gemelos celestiales con quienes tiene dos hijos: Nakula y Sahadeva. Curiosa coincidencia, pues al igual que con Bhīşma, el nacimiento de estos cinco hermanos - los protagonistas de la batalla - se produce mediante una maldición.

Pero sigamos con la historia. Un día Pāndu cede ante la irresistible belleza de Mādrī y fallece a causa de la maldición. Sintiéndose culpable, Mādrī decide morir junto a su esposo dejando a sus dos hijos con Kunti. Estos cinco hermanos son llamados pāndavas. Por otro lado, nacen los cien hijos del rey ciego, siendo Duryodhana y Dusaāsana los mayores. Estos cien hermanos son llamados kauravas. Tras la muerte de su esposo, la reina Kunti regresa al reino con los cinco pāndavas, quienes reciben educación por parte de Bhīşma y otros maestros. Los cinco hermanos, también llamados kaunteyas, destacan en el uso de diferentes armas, pero también sufren un ambiente de hostilidad, rivalidad y conspiración de parte de sus primos. Esta rivalidad y la injusticia de parte del rey ciego Dhrtarasţra, quien quiere que su hijo mayor sea el rey, son algunos de los antecedentes a la batalla de Mahäbhärata entre los pāndavas y kauravas.

En general, a lo largo de todo el libro y en la batalla en específico, Krş̧ya juega un papel central. Aunque participa como auriga de Arjuna en la guerra, Kŗ̧̧̧̧a no pelea ni usa ninguna arma, sino que sirve de estratega principal de los pāndavas para eliminar a los contrincantes más fuertes, invencibles e inmortales. Con la constante ayuda y orientación de Krş̧ya, la batalla termina a favor de los cinco virtuosos hermanos. Mas, cuando él llega con Gāndhāri, la inconsolable madre de los derrotados y muertos kauravas, ésta lo nombra el verdadero culpable y responsable de la batalla. Por lo tanto, maldice la dinastía de Krş̧̧a profiriendo que morirán matándose los unos a los otro en una pelea. Siendo una encarnación del dios supremo, Krş̧̧a es capaz de rechazar

33 Es uno de los nombres del dios de la Muerte. En este contexto significa el dios de la Ética.

34 Dios del Viento. 
esta maldición; no obstante, la acepta porque, como argumenta el profesor Benjamín Preciado en su artículo sobre Mausalparvan, " $[\ldots]$ he is only fulfilling his role as nemesis, making truthful each and every vow and curse made [...]"35 (Preciado 2005: 244).

Incluso después de que termina la batalla, el libro continúa con ocho capítulos más, además de un apartado dedicado específicamente a la vida de Kŗ̧̧̧a. No será posible analizar en este artículo, cada ocasión en la que el uso del poder de la palabra - sea en forma de bendición o de maldición - se presenta en el libro; sin embargo, quisiera concluir con algunas reflexiones tomando en cuenta los ejemplos que mencionamos.

En la epopeya que gira alrededor de la batalla entre los parientes de una familia, el nacimiento de la mayoría de los personajes principales se debe al poder de la palabra, sea en la forma de maldición o bendición; por ejemplo, Bhīşma, un ser celestial encarcelado en el cuerpo de un ser humano; los pāndavas, en vez de nacer de su padre biológico, son descendencia o "representación" de las fuerzas divinas gracias al poder de un mantra que posee su madre; la dinastía de Krş̧ya (y él mismo, a pesar de ser la fuerza suprema) encuentra su fin "gracias a una maldición". Verdaderamente será difícil clasificar estos usos variados del poder de la palabra como śāpa o vara.

Es posible observar que, en las escrituras sagradas del hinduismo, nadie está libre de o es inmune a la maldición, ni hombres ni dioses. Sólo aquel que profiere la maldición tiene el poder de apaciguar o reducir el castigo. Esto podría parecer contradictorio, ya que supuestamente los sabios tienen perfecto dominio sobre sus instintos - ira, deseo, arrogancia o soberbia, entre otros-, pero son ellos los que deciden lanzar maldiciones. Lo más sorprendente es que hasta las fuerzas supremas (Kŗ̧̧̧a o Viş̧u, por ejemplo), aun teniendo la capacidad y la posibilidad de ser inmunes a estos "castigos", los aceptan, ya que, según varios textos filosóficos y religiosos antiguos, todo lo que sucede no es más que un jugueteo (Līlā) ${ }^{36}$ o una ilusión (Māyāa) ${ }^{37}$ creados por la fuerza

\footnotetext{
35 "[...] él solo está cumpliendo su papel como nemesis, haciendo la verdad cada uno de los votos (que se toma) y cada maldición (que se da)".

36 En el hinduismo, todo aquello que sucede es una $L \bar{l} l \bar{a}$ de las fuerzas superiores. Se puede traducir como "juego" o "jugueteo".

37 Por lo general, se traduce como ilusión (divina).
} 
suprema misma. Y en este jugueteo, el uso del poder de la palabra, o las maldiciones, no son más que los catalizadores que dan nuevos rumbos a esta comedia divina que, vista desde una perspectiva limitada, parece una tragedia humana.

\section{Bibliografía}

Eulate, Carmela (adapt.) (2002). Sakuntala de Kalidasa. México, Porrúa.

Preciado Solís, Benjamín (2005). "The Episode of the Mausalparvan", en T. S. Rukmani (ed.), The Mahabharata, what is not here is nowhere else, Yannehasti na Tadkvacit, Nueva Delhi, Munshiram Manoharlal Publishers, 239-244.

Vātsyayanamuni, Sri (1999). Kämasutram, comentario de Sri Yasodhara. India, Ed. Dr. Parasa Nath Dwivedi, Chatukhamba Surbharati Prakashan.

Vyāsa (s. f.), Mahabharata. Disponible en: <http://www.sacred-texts.com/ hin/maha/index.htm>; consultado por última vez el 19 de junio de 2017.

- (2004). Srimadbhagavat-Sudha-Sagar. Shantanu Bihari y Saraswati Akhandananda (trads.). India, Geetapress.

WiLkins, W. J. (1900). Hindu Mythology, Vedic and Puranic. Calcuta, Thacker, Spink \& Co.; Londres, W. Thacker \& Co. 